\title{
Las transformaciones de la relación salarial durante los noventa y su impacto en las convenciones colectivas de trabajo del Sindicato Unido Petroleros del Estado (SUPE)
}

\author{
Transformations of wage relation in the nineties and their impact in \\ the collective bargaining agreement of Sindicato Unido Petroleros \\ Del Estado (SUPE)
}

\author{
María Lorena Capogrossi*
}

\begin{abstract}
RESUMEN
En este artículo analizaremos las transformaciones que tienen lugar en la esfera del trabajo a partir de las reformas estructurales implementadas en Argentina durante la década del 90. En el caso de Yacimientos Petrolíferos Fiscales, las innovaciones en las relaciones sociales de producción se evidencian con mayor nitidez desde que el ingeniero José Estenssoro es designado interventor de la firma en agosto 1990. La puesta en marcha de un programa de racionalización del personal desde ese año y la incorporación de dispositivos de flexibilización laboral en las Convenciones Colectivas de Trabajo del sector petrolero muestran un aspecto de las modificaciones en el modelo de acumulación iniciado a mediados de los 70: el debilitamiento del movimiento obrero organizado y los obstáculos a los que se enfrenta para construir nuevos modelos organizativos que le permitan defenderse con eficacia de los embates del capital.
\end{abstract}

Palabras Clave: Flexibilización laboral. Relación capital/trabajo. YPF. Convenios colectivos de trabajo. Sindicatos petroleros.

\section{ABSTRACT}

This article analyses the transformations taking place in the world of work from the structural reforms implemented in Argentina during the 90s. In the case of $\mathrm{YPF}$, innovations in the social relations of production are more clearly evident from the engineer J osé Estenssoro is appointed auditor of the firm in August 1990. The implementation of a staff rationalization program from that year and devices incorporating labor flexibility in labor agreements in the oil sector showing an aspect of the changes in the accumulation model initiated in the mid-70: the weakening of organized labor and the obstacles it faces in building new organizational models that allow you to effectively defend themselves from the ravages of capital.

KEYWORDS: Labor flexibility. Labor capital relationship. YPF. Collective Bargaining Agreement. Oil workers union.

\footnotetext{
* Lic. en Historia. Becaria doctoral CONICET. Programa Antropología e Historia de la relación capital- trabajo en el contexto contemporáneo- Centro de Estudios Avanzados-Unidad Ejecutora de CONICET.
} 


\section{Contextualización Introductoria}

En este artículo analizaremos las transformaciones que tienen lugar en la esfera del trabajo a partir de las reformas estructurales implementadas en Argentina durante la década del 90. Particularmente, nos detendremos en el período que sigue a la puesta en marcha del Plan de Convertibilidad impulsado por el entonces Ministro de Economía, Domingo Cavallo, y al ingreso del Plan Brady, cuando las diferentes líneas de capital se encuadran y enfrentan como bloque dominante al trabajo, llegando a alcanzar el momento político. ${ }^{1}$

El proyecto de ley de convertibilidad del austral es promulgado por el Congreso de la Nación en marzo de 1991 y entra en vigencia a partir del 1 o de abril del mismo año. Por el artículo 1 de la Ley 23.928 se establece la "Convertibilidad del austral con el Dólar de los Estados Unidos de América [...] a una relación de DIEZ MIL AUSTRALES (A 10.000), por cada dólar [...]".2 El objetivo de esta ley es lograr la estabilidad de precios a largo plazo lo que, sumado a la apertura comercial, impide que las diferente líneas de capital presionen al Estado, como lo hicieron durante los brotes hiperinflacionarios de 1989 y 1990. De este modo se disciplina a los actores locales mediante la competencia externa, inhibiéndolos de aumentar los precios.

Paralelamente, el Plan prohíbe utilizar las variaciones del índice de precios al consumidor (IPC) - que señalan la evolución del costo de vida - para reajustar precios y salarios. ${ }^{3}$ Esto último puede ser comprendido a partir de cierto supuesto de la vertiente neoliberal que sostiene que si se presiona para que bajen los salarios, disminuye la tasa de desempleo porque "los precios (costo laboral) deberán ser la expresión de la escasez relativa de mano de obra" (apud MUSACCHIO, 2002, p. 278). Tal situación quedó patentada en las sugerencias hechas por Cavallo a los empresarios en una reunión mantenida en febrero de 1992 cuando intentó convencerlos de que "no

1 Esto es, llegan a la "[...] fase en la cual las ideologías ya existentes se transforman en «partido», se confrontan y entran en lucha hasta que una sola de ellas [...] tiende a prevalecer [...] a difundirse por toda el área social, determinando además la unidad de los fines económicos y políticos, la unidad intelectual y moral, planteando todas las cuestiones en tormo a las cuales hierve la lucha no sobre un plano corporativo sino sobre un plano universal y creando así la hegemonía de un grupo social fundamental sobre una serie de grupos subordinados" (GRAMSCI, 1995, p. 57-58).

2 Congreso de la Nación Argentina, Ley 23.928. 28 de marzo de 1991.

3 Dice el artículo 10 de la Ley 23.928 (28 de marzo de 1991): "Deróganse, con efecto a partir del 1o del mes de abril de 1991, todas las normas legales o reglamentarias que establecen o autorizan la indexación por precios, actualización monetaria, variación de costos o cualquier otra forma de repotenciación de las deudas, impuestos, precios o tarifas de los bienes, obras o servicios. Esta derogación se aplicará aun a los efectos de las relaciones y situaciones jurídicas existentes, no pudiendo aplicarse ni esgrimirse ninguna cláusula legal, reglamentaria, contractual o convencional -inclusive convenios colectivos de trabajo- de fecha anterior, como causa de ajuste en las sumas de Australes que corresponda pagar, sino hasta el día 1o de abril de 1991, en que entra en vigencia la convertibilidad del Austral". 
deben aumentar los salarios de sus empleados ante el peligro de un [...] rebrote de la inflación".4

Mirando retrospectivamente, en Argentina ocurrió exactamente lo contrario a lo vaticinado por los intelectuales orgánicos del neoliberalismo porque, haciendo una progresión, podemos observar que los niveles de desocupación aumentaron, pasando de un 6,1 \% en octubre de 1988 al 17, $3 \%$, en octubre de $1996^{5}$ y, paralelamente a ello, los salarios reales básicos por convenio del personal calificado descendieron un 29,9\% en diez años (1988-1998), mientras que los del personal no calificado lo hicieron en un 29 \% en igual período (MUSACCHIO, 2002, p. 283).

Esto nos muestra, en realidad, que la desocupación masiva que siguió a la privatización de las empresas públicas fue funcional al capital porque creó un ejército industrial de reserva ${ }^{6}$ que presionó sobre los salarios de los trabajadores ocupados, haciéndolos bajar cada vez más y “[...] brindándole al capital] el material humano, dispuesto siempre para ser explotado a medida que lo reclamen sus necesidades variables de explotación, independiente, además, de los límites que pueda oponer el aumento real de población [...]" (MARX, 1999, p. 535). Esto avala la hipótesis de que las organizaciones que representan a los trabajadores de las empresas a privatizar no lograron solidificar una alianza con la fuerza suficiente como para combatir el proceso de "racionalización" de personal y flexibilización laboral.

Este proceso que mencionamos también formó parte de la profundización de la Reforma del Estado, establecida por la Ley 23.696/89, y del programa de privatizaciones. El objetivo, en este caso, se hallaba vinculado a la necesidad de equilibrar las cuentas fiscales a través de la reducción del gasto y el aumento de los ingresos regulares y transitorios. Estos últimos estaban constituidos por la venta de activos públicos. Sin embargo, el cuello de botella para el éxito del Plan Cavallo lo constituía el tema de la deuda externa puesto que sin la confianza de los acreedores, era imposible sostener estas medidas a largo plazo. De ese modo, el 7 de abril de 1992, el país ingresa al Plan Brady abriéndose a partir de entonces la posibilidad de reestructurar el cronograma de pagos con los acreedores externos. ${ }^{7}$ En un artículo del

4 Microsemanario, Año 2.4 al 11 de febrero y 11 al 18 de febrero de 1992.

5 INDEC. Encuesta Permanente de Hogares. Años 1974-2003

6 “[...] si la existencia de una superpoblación obrera es producto necesario de la acumulación o del incremento de la riqueza dentro del régimen capitalista, esta superpoblación se convierte a su vez en palanca de la acumulación del capital, más aún, en una de las condiciones de vida del régimen capitalista de producción. Constituye un ejército industrial de reserva, un contingente disponible, que pertenece al capital de modo tan absoluto como si se criase y se mantuviese a sus expensas" (MARX, 1999, p. 535)

7 Microsemanario. Año 2 № 57.7 al 13 de abril de 1992. 
periódico Microsemanario se anticipan las consecuencias de esta negociación de Cavallo con los acreedores:

\begin{abstract}
Entrar al Brady significará para la Argentina un espaldarazo para su política de radicación de inversiones extranjeras pero al mismo tiempo una hipoteca por los próximos 30 años ya que no existe renegociación posible [...]. Por otra parte, excepto la masa de tesoro acumulado que sustenta al Peso (por la ley de Convertibilidad tantos dólares y oro como dinero hay en la calle) el resto puede ser girado al exterior para el pago de la deuda, es decir que se generará superávit fiscal con el fin de saldar acreencias $[. . .]^{8}$.
\end{abstract}

Tanto el Plan Cavallo como el acuerdo con los organismos internacionales, son acompañados por una serie de reformas estructurales que terminan haciendo converger a las diferentes líneas de capital concentrado local y a los acreedores externos. Entre esas reformas, una de las más importante es la privatización de las empresas públicas, proceso llevado a cabo con una premura inédita, en tanto que hacia 1994 el proceso prácticamente había concluido (BASUALDO; AZPIAZU, 2004; ASPIAZU; SHORR 2001).

Los ingresos obtenidos por el gobierno a partir de estas transferencias permiten nivelar la balanza de pagos, estabilizando los niveles de endeudamiento. Esto es posible porque la ley de Reforma del Estado, permite capitalizar los bonos de la deuda externa, es decir, los acreedores de títulos de la deuda pueden canjearlos como parte de pago de los activos públicos transferidos y con ello el Estado reduce su pasivo. El Decreto 2074/ 90 en su artículo 23, faculta al Poder Ejecutivo Nacional, con anuencia de la cartera económica, a "la utilización de reconversión y capitalización de deuda externa” en los procesos de privatización. ${ }^{9}$ Esto, en términos de Azpiazu y Shorr (2001, p. 26), significó “[...] el desarrollo de una estrategia política que no sólo buscó integrar al núcleo hegemónico de la economía argentina a la fracción dominante «excluida» durante buena parte de la década de los ochenta, sino que también permitió que la Argentina ingresara, en 1992, al primer «megacanje» de deuda de los noventa [...]”.

A través de las privatizaciones se obtuvo un ingreso fiscal cercano a los 13.000 millones de dólares (BASUALDO; ASPIAZU, 2004, p. 88) y las diferentes líneas de capital consiguen ingentes beneficios por desembolsos magros, en tanto los activos de las empresas a privatizar son subvaluados.

Así mismo, se profundiza el proceso de concentración de capital porque el llamado a licitación favorece la presentación de pocas empresas en los concursos en tanto uno de los requisitos fundamentales que se tuvieron en cuenta a la hora de las

8 Microsemanario, Año 2 № 47. Enero de 1992

9 Boletín Oficial. Decreto 2074. 5 de octubre de 1990 
transferencias fue la fijación de montos patrimoniales muy elevados que dejaron fuera de competencia a numerosos sectores.

Un aspecto fundamental que permite a estos sectores asegurar sus beneficios es la racionalización de personal encarada por el Estado antes de proceder a la venta de sus empresas. ${ }^{10}$ Ese proceso de racionalización había sido contemplado por la Ley de Emergencia Económica e involucraba traslados de personal de una dependencia a otra, retiros voluntarios - previo pago de una indemnización - y jubilaciones anticipadas, a fin de asegurar la rentabilidad posterior de la empresa a privatizar. ${ }^{11}$ Con ello se consigue aumentar la productividad, reduciendo la parte variable del capital, esto es, la participación de los salarios en el total. La Central de los Trabajadores Argentinos, en un documento elaborado por su Instituto de Estudios y Formación explica cuáles es el significado de este aumento de la productividad:

[el aumento de la productividad] se tradujo en una notoria caída de la participación de los asalariados en el valor agregado de las empresas privatizadas. El efecto de las privatizaciones fue, desde este punto de vista, doble. Por una parte concentró el ingreso dentro del sector privatizado. Por otra parte incrementó la desocupación global y deterioró la capacidad negociadora de los trabajadores con sus empleadores, lo cual fue un elemento adicional de concentración del ingreso a favor de las utilidades en la sociedad en su conjunto (CENTRAL DE LOS TRABAJ ADORES ARGENTINOS, 2011).

Los casos más notables de reducción del plantel laboral en el período son los de Ferrocarriles Argentinos, cuyo plantel laboral se redujo de 94.216 empleados en 1989 a 15.739 en 1998, y el de YPF, que pasó de una máxima de 36.935 empleados en 1990 a 10.103 en 1994.12

Estas cifras revelan que la Reforma del Estado es un reflejo de los reacomodamientos del capitalismo argentino, reacomodamientos operados en la relación capital-trabajo y que evidencian la consolidación de un patrón de acumulación

\footnotetext{
${ }^{10}$ Esto ocurre porque “[...] el aparato de Estado actúa para dar sustento normativo, ideológico, y si es necesario represivo a la reestructuración del proceso de acumulación del capital, realizada en gran medida, en base al aumento de la explotación de la fuerza de trabajo. El término clave para caracterizar la acción estatal en este campo, es la desregulación, o su casi equivalente flexibilización" (MUÑOZ; CAMPIONE, 1994, p. 77).

${ }^{11}$ Los agentes desvinculados de las empresas públicas, vía retiros voluntarios, en el período 19911993, es la siguiente, según estimaciones de la Subsecretaría de Privatizaciones dependiente de la Secretaría de Hacienda de la Nación: en Yacimientos Petrolíferos Fiscales, 22.208 agentes; en Yacimientos Carboníferos Fiscales, 1277 agentes; en Gas del Estado, 1170 agentes; en Segba, 2741 agentes; en Agua y Energía Eléctrica, 3134; en Hidronor, 100 agentes; en Ferrocarriles Argentinos, 27.419 agentes; en FEMESA, 1825 agentes; en Encotel, 4000; en Elma, 2140 y en AGP, 675. Lo cual nos da un total de 66.789 personas que aceptaron los retiros voluntarios. Citado por Redondo (1997).

${ }^{12}$ El total de empleados de YPF referido aquí tiene en cuenta sólo la planta permanente, no el personal contratado.
} 
que tiene sus pilares en la obtención de renta y en la especulación financiera (TRINCHERO; LEGUIZAMÓN, 2004; BALAZOTE; RADOVICH, 2003).

$\mathrm{Si}$ al "proceso de racionalización" que venimos describiendo, le sumamos las transformaciones en la legislación laboral desde que Cavallo asume como Ministro, tendremos un panorama complejo en lo que se refiere a conquistas del movimiento obrero porque se pone en movimiento un proceso donde el Estado se retira dejando de garantizar la reproducción de la fuerza de trabajo. ${ }^{13}$ A partir de entonces su acción se centra en suprimir aquellos aspectos que limiten la libre explotación del trabajo por el capital. Esto se realiza en dos niveles: a) en el nivel del mercado de trabajo, a través de la precarización del empleo, los contratos por tiempo determinado y los recortes o la supresión de indemnizaciones, y b) en el nivel del proceso productivo, a través de la polivalencia funcional del trabajador, la variabilidad de la jornada de trabajo, etc. La condición para su viabilización supone compartimentar la negociación laboral, desplazando los convenios colectivos por negociaciones a nivel de empresa o rama productiva (MUÑOZ; CAMPIONE, 1994, p. 77; NEFFA, 1998, p. 344). Etchemendy y Palermo señalan tres dimensiones del concepto de reforma laboral que engloban los puntos que mencionamos anteriormente: la flexibilización vinculada al derecho individual del trabajo, las reformas asociadas al derecho colectivo, y las que fortalecen al capital en las negociaciones y en sus cargas sociales (ETCHEMENDY; PALERMO, 1998, p. 562).

En este sentido, el puntapié inicial fue el Decreto 1334, de julio de 1991, que subordina los aumentos salariales al incremento de la productividad, lo que muestra la tendencia "hacia la descentralización de las instancias de constitución de las relaciones laborales" (NOVIK, 2001, p. 32). ${ }^{14}$ A esa norma le siguió el Decreto 2284 de octubre del mismo año que tenía ingerencia, entre otras cosas, en las negociaciones colectivas. A partir de entonces las negociaciones pueden ser por actividad, por empresa, por oficio o

13 Para ampliar la información respecto a las reformas laborales durante el período. (ETCHEMENDI; PALERMO, 1998).

14 En marzo de 1992 la CGT se reunifica para oponerse al plan de reforma de las obras sociales y asume Oscar Lazcano (Luz y Fuerza) la conducción de la central obrera. Su primera medida es exigir la derogación del Decreto 1334, que es acompañada por el anuncio de un paro general para julio de 1992. Esta acción finalmente se levanta cuando, luego de una reunión con el ministro Cavallo, la central negocia la recuperación de las obras sociales para los sindicatos. Cfr. Microsemanario. Año 2. № 55 y № 71.24 al 30 de marzo de 1992 y 13 al 19 de julio de 1992. A fines del año anterior había tenido lugar la fundación del Congreso de los Trabajadores Argentinos formado por los trabajadores de CETERA, ATE y la izquierda del ubaldinismo. En la declaración que emiten, cuestionan el "viejo modelo sindical" y sostienen que los estrechos vínculos de los conductores de la CGT con el menemismo les impide canalizar las demandas de los trabajadores argentinos. Serán ellos los que impulsen posteriormente las marchas federales y en 1996 funden CTA (GODIO, 2000, p. 1196). 
rama de actividad ${ }^{15}$, lo cual significa avanzar en el socavamiento del poder de negociación de las instituciones que organizan al movimiento obrero. Así mismo, en las disposiciones generales se establece un régimen de retiro voluntario,

[...] para el personal de organismos disueltos que no sea transferido a otros
organismos públicos o bien a las empresas privadas que tomen a su cargo la
explotación de las instalaciones de estos organismos [...]". Estableciéndose
que aquellos que se acojan a este régimen percibirán una indemnización “[...]
equivalente de un mes de remuneración por cada año de antigüedad o fracción
mayor de TRES (3) meses, más un VEINTE POR CIENTO (20\%). Dicho
importe será liquidado en SIETE (7) cuotas mensuales iguales y
consecutivas ${ }^{16}$.

A ese decreto le siguió la sanción de la Ley Nacional de Empleo № 24.013 en noviembre de 1991 que incorpora nuevas modalidades de contratación por tiempo determinado, estipulando el $50 \%$ de rebajas a las cargas patronales para quienes tomen personal según estas modalidades (Artículo 28) 17; se fijan topes a las indemnizaciones por despido injustificado (Artículos $111 \mathrm{al} 127)^{18}$ y se crean procedimientos preventivos para empresas en situación de crisis (Artículos 98 al 105). ${ }^{19}$ Paralelamente se obliga a que las comisiones negociadoras de los Convenios Colectivos de Trabajo atiendan a aspectos vinculados a las relaciones laborales, como capacitaciones que faciliten la polivalencia funcional de los trabajadores (Artículo 24$)^{20}$ y se establecen medidas de fomento del empleo digitadas por el Ministerio de Trabajo y Previsión Social destinadas a la asistencia técnica y capacitación para cooperativas, programas de propiedad participada y empresas formadas por trabajadores (Artículos 90 al 94) ${ }^{21}$, que en la práctica distaron de funcionar, como en el caso de Yacimientos Petrolíferos Fiscales.

A lo largo del período se fue profundizando esta tendencia a la flexibilización de las relaciones laborales, pero el punto de inflexión fue en 1995 con la sanción de la Ley 24.465 que modifica el Régimen de Contrato de Trabajo. Esta ley incorpora como artículo 92 bis el período de prueba por tres meses en los contratos laborales, pudiendo ser extinguida la relación sin causa justificada y sin que ello implique el pago de una indemnización. Así mismo se incorporan los contratos de aprendizaje; las medidas de fomento del empleo que permiten al empleador contratar a discapacitados, mujeres y personas de más de cuarenta años a cambio de ser eximidos del $50 \%$ de las contribuciones patronales al sistema de seguridad social ${ }^{22}$ y los contratos de tiempo

15 Artículos 104 y 105. En: Poder Ejecutivo Nacional: Decreto 2284. 30 de octubre de 1991

16 Artículos 106 a 108.

17 Digesto A.z , 1997, p. 106.

18 Digesto A.z , 1997, p.124-130.

19 Digesto A.z, 1997, p. 122-123.

20 Digesto A.z, 1997, p. 105.

21 Digesto A.z , 1997, p. 120-121.

22 Congreso de la Nación Argentina: Ley 24.465. 23 de marzo de 1995. 
parcial. Las modificaciones en el Régimen de Contrato de Trabajo, no sólo hacen desaparecer conquistas históricas de la clase obrera argentina, como la indeterminación del contrato laboral, sino que precarizan la situación de numerosos trabajadores y apuntalan el proceso de acumulación del capitalismo argentino.

$\mathrm{Si}$ tenemos en cuenta los datos del INDEC para el período veremos que en octubre de 1989 la desocupación era del 7,1\% y la subocupación horaria ${ }^{23}$ del 8,6; mientras que una década después el porcentaje de personas sin trabajo ascendía al 13,8 $\%$ y de los subocupados al $14,3 \%{ }^{24}$

Para autores como Castel, esto supone la emergencia de una nueva "cuestión social" que es resultado de las exigencias científico tecnológicas del capitalismo moderno y que, a nivel trabajo, cristaliza en tres aspectos: 1) la "desestabilización de los estables", es decir, de aquellos trabajadores que anteriormente se encontraban integrados; 2) la "instalación de la precariedad" del empleo, que supone la alternancia entre períodos de actividad e inactividad ${ }^{25}$ y; 3) la manifestación del punto anterior es el "déficit de lugares ocupables en la estructura social", que se traduce en la existencia de supernumerarios que pasan a erigirse en "no-fuerzas sociales" (CASTEL, 1998, p. 414-416).

En el caso argentino, podemos entrever que se produjo un paradoja en el ámbito del movimiento obrero organizado, porque si lo que otorga identidad al sindicalismo desde el 45 en adelante es la defensa colectiva de los intereses del trabajador, sobre todo, en aquello vinculado a la permanencia en el empleo, a partir de la puesta en práctica de todos los mecanismos que venimos mencionando hasta aquí, esa función se torna difusa y dejan de existir aquellas garantías que fortalecen la capacidad de lucha de las organizaciones de los trabajadores (BATTISTINI, 2002, p. 44).

\section{Desregulación y Racionalización de Personal en el Sector Petrolero}

En este apartado analizaremos las modificaciones en la relación salarial en un ámbito productivo particular: Yacimientos Petrolíferos Fiscales. Las leyes de Emergencia Económica y Reforma de Estado, repercutieron en la organización de la empresa petrolera estatal y en las relaciones capital/trabajo dentro de la firma. Pero

23 La subocupación horaria se calcula como porcentaje entre la población subocupada y la población económicamente activa (PEA). Se considera como población subocupada aquella que trabaja menos de 35 horas semanales por causas involuntarias y que están buscando mejores condiciones laborales.

24 INDEC: Encuesta Permanente de Hogares. Años 1974-2003

25 Castel (1998, p. 415) sostendrá esta situación genera "[...] una cultura que [...] es una «cultura de lo aleatorio». Así, ha vuelto a primer plano de la escena social una obligación muy antigua impuesta a lo que hoy llamaríamos el pueblo «vivir al día». ¿No hay derecho a hablar de un neopauperismo?”. 
antes de abocarnos en el tema específico, creemos necesario reseñar brevemente el proceso que condujo a la privatización de la petrolera estatal.

Alejandro Rofman (1999) distingue dos etapas dentro del proceso que condujo a la enajenación del capital accionario de Yacimientos Petrolíferos Fiscales. La primera supuso la transferencia de áreas de explotación al capital privado y estuvo normatizada por una serie de decretos del poder ejecutivo, que claramente se orientaban a desregular el sector. Esta primera etapa se llevó adelante obviando cualquier intento de consenso con los trabajadores y habitantes de las regiones donde se realizaban los procesos productivos vinculados al petróleo.

Si bien el proceso se inicia en octubre de 1989 con el Decreto № 1055, cuyo objetivo es mejorar la competencia en el sector a través de una progresiva desregulación, nosotros nos detendremos únicamente en la norma que repercute de manera directa en la relaciones entre capital y trabajo. Estamos haciendo referencia al Decreto 2778/90 que dispone la transformación jurídica de YPF. La justificación argüida en sus considerandos es la necesidad de "alcanzar una gestión eficiente y transformarla en una empresa competitiva en un mercado desregulado y desmonopolizado", regida por el derecho privado. Para alcanzar tal objetivo se diseña un Plan de Transformación Global de la petrolera que “[...] presupone mantener aquellos activos productivos que empresarialmente son estratégicos y económicamente viables, vendiendo los demás activos o asociándose en su explotación cuando su operación implique grandes inversiones y riesgos". ${ }^{26}$ Lo que se espera con el Plan es asegurar la rentabilidad a los futuros accionistas de una YPF que se orienta definitivamente hacia su privatización.

La segunda etapa identificada por Rofman tiene como eje la transferencia a manos privadas del capital accionario mayoritario de Yacimientos Petrolíferos Fiscales. Esto cristaliza con la sanción de la Ley de Federalización de Hidrocarburos. sancionada en octubre de 1992. El debate y aprobación del proyecto presentado por el oficialismo es pospuesto en varias ocasiones porque la oposición se negaba a dar quórum ante lo que consideraba una entrega del patrimonio nacional. Algo que llamó nuestra atención al leer los Diarios de Sesiones fue que muy pocos argumentos tanto a favor como en contra del proyecto se refirieron a las reestructuraciones que la privatización provocaría en los perfiles productivos, sociales y económicos de las regiones que habían crecido en torno a Yacimientos Petrolíferos Fiscales. Por el contrario, la mayoría de los juicios emitidos por diputados y senadores se centraron en

26 Poder Ejecutivo Nacional. Decreto 2778. 31 de diciembre de 1990. 
el tema de la federalización de la propiedad de los hidrocarburos, en los sectores que serían beneficiados a partir de la privatización de la petrolera y en el grado de competitividad que alcanzará la empresa a partir de la venta de activos al capital privado.

Durante el debate de la ley, el oficialismo negó las acusaciones de la oposición de que con la Ley 24.145 se favorecería a los sectores más concentrados del capital privado extranjero. Sin embargo, al seguir la trayectoria de la privatización vemos que, una vez realizada la primera oferta pública internacional en 1993, quienes se quedan con el 58\% del capital social de YPF fueron: Fidelity, el principal fondo de pensión del mundo; el Citibank, que para entonces se erigía como el mayor acreedor del país; Pérez Companc y un fondo de inversión - Argentina Private Development Trust (APDT)- , integrado por Pérez Companc y por bancos acreedores como el Midland Bank, el Banco de Tokyo y la Corporación Financiera Internacional (subsidiaria del Banco Mundial). ${ }^{27}$

Lo cierto es que tras la esa primera colocación de acciones en el mercado, el sector privado se queda con el 45,3\% del capital accionario de Yacimientos Petrolíferos Fiscales y el resto permanece en manos de las provincias, el Estado Nacional y los ex agentes petroleros (ROITTER, 1994, p. 115). No obstante, la estructura del capital social de la petrolera vuelve a modificarse a lo largo de los años para, en 1999, quedar constituida de la siguiente manera:

Tabla 1 - Estructura accionaria de YPF S.A. Año 1999.

\begin{tabular}{|c|c|c|}
\hline $\begin{array}{c}\text { Estructura del capital } \\
\text { accionario de YPF SA, inicio } \\
\text { y fines de } 1999 \text { En \% de } \\
\text { acciones } \\
\end{array}$ & & \\
\hline \multirow[t]{2}{*}{ Accionista } & $\begin{array}{c}\text { Participación } \\
\text { accionaria (en } \\
\text { porcentajes) }\end{array}$ & \\
\hline & Inicios de 1999 & Fines de 1999 \\
\hline Estado Nacional & $5 \%+$ acción de oro & Acción de oro \\
\hline Estados Provinciales & $4,7 \%$ & $0 \%$ \\
\hline Agentes de YPF & $0,4 \%$ & $0,4 \%$ \\
\hline Repsol & $14,99 \%$ & $98,23 \%$ \\
\hline Otras empresas privadas & $74,90 \%$ & $1,37 \%$ \\
\hline
\end{tabular}

Fuente: Elaboración propia en base De Dicco (2004. p. 14).

27 Microsemanario. Año 3, n. 113, 5 al 18 de julio de 1993. 
A continuación nos detendremos en las modificaciones que el proceso abierto desde 1989 generó en las relaciones laborales del sector.

\section{Las Transformaciones de la Relación Capital-trabajo en YPF}

Respecto al personal de la empresa, desde que el ingeniero J osé Estenssoro es nombrado interventor de YPF en agosto de 1990, se pone en marcha un doble proceso: por un lado, una reducción de costos que supuso la disminución del número de agentes en la medida en que desde estos años la fuerza de trabajo pasa a formar parte de la categoría "costos" del capital; y por el otro, la cristalización de pautas de flexibilización laboral y aumentos de la productividad por trabajador a lo largo de los años que reflejan las transformaciones operadas en las relaciones laborales y que se patentizan en las modificaciones de los Convenios Colectivos de Trabajo de 1990, 1993 y 1997.

El primero de estos procesos supuso la reducción de la planta de personal de la firma, que pasó de estar constituida por 51.000 trabajadores en 1990 - entre contratados y efectivos - , a poseer 7500 en diciembre de 1993 (ROITTER, 1994, p. 109; DE DICCO, 2004, p. 9).

En la tabla que reproducimos a continuación pueden observarse las causas principales de la reducción de personal durante los años de transformación vertiginosa de la empresa:

Tabla 2- Número de despidos y causas de reducción del plantel laboral de yacimientos petrolíferos fiscales. total del país. Años 1990-1994

\begin{tabular}{|c|c|c|}
\hline Causa & Año 1991 & $\begin{array}{c}\text { Desde agosto de 1990 a } \\
\text { septiembre de 1994 }\end{array}$ \\
\hline $\begin{array}{c}\text { Despidos con } \\
\text { indemnizaciones y } \\
\text { retiros voluntarios }\end{array}$ & 12.507 & 30.383 \\
\hline J ubilaciones & 839 & 1.328 \\
\hline Rescisión de contratos & 134 & 953 \\
\hline Renuncias & 229 & 658 \\
\hline Fallecimientos & 88 & 216 \\
\hline
\end{tabular}

Fuente: Elaboración propia en base a datos extraídos de Herrera y García (2003).

Las modalidades adoptadas para agilizar el proceso de desvinculación del personal de la empresa, además de las jubilaciones anticipadas y las renuncias, fueron cuatro: 1) Por reducción o eliminación de áreas dentro de YPF y en cada región. En virtud de estas transformaciones, el personal que no podía ser reabsorbido perdía su puesto de trabajo; 2) Por terciarización de servicios. En este caso, desde YPF se 
fomenta la creación de cooperativas y micro-emprendimientos a cargo de agentes desvinculados de la empresa. A estas pequeñas firmas se les transfieren en comodato o se les venden en cuotas, máquinas y equipos que antes pertenecían a la petrolera estatal y se les concede exclusividad en la prestación de servicios por dos años. (FEDERACIÓN DE LOS TRABAJ ADORES DE LA ENERGÍA DE LA REPÚBLICA ARGENTINA, 2011). Una vez transcurrido ese período, los emprendimientos productivos pasan a competir en el mismo nivel que las grandes empresas proveedoras de insumos y servicios petroleros; 3) Por mecanismos de reconversión laboral en virtud a la nueva condición jurídica de la empresa. Estos dispositivos entrañan pases compulsivos al área de Gerencia de Capacitación de 5000 agentes por año. Al ypefiano se le hace elegir el curso que quiera realizar y por el lapso de un año, efectúa la capacitación sin dejar de percibir sus haberes y sin perder sus beneficios sociales; 4) Los retiros voluntarios. Esta modalidad se incorpora a partir de la sanción del Decreto 2284 de octubre de 1991 que, en sus disposiciones generales, establece un plazo de 30 días para adherir al régimen de retiro en organismos a privatizar o donde se esté realizando un plan de racionalización. Los trabajadores que no suscriban a esta modalidad pasan a disponibilidad o son despedidos. Un año después vuelve a utilizarse el mecanismo de decreto pero, esta vez, para exhortar a los interventores o autoridades de las empresas que atraviesen planes de racionalización a definir qué dotación de personal es realmente necesaria para cumplir con las actividades de los entes intervenidos. ${ }^{28} \mathrm{~A}$ manera de ejemplo, Paula Klachko registra el Télex № 023142 de septiembre de 1991 del Vicepresidente de Recursos Humanos de YPF, Héctor Oreste, en el que queda registrado lo que decimos "[...] la empresa advierte que aquellos agentes que deseen desvincularse de la misma en forma voluntaria no dilaten la decisión, toda vez que en los próximos días podría producirse una sensible disminución de los montos indemnizatorios a percibir [...]" (apud KLACHKO, 2005, p. 44). Otro punto conflictivo del decreto es que determina que "Los trámites de retiro voluntario en todos los casos deberán iniciarse en forma individual a partir de la solicitud que en tal sentido formulen los trabajadores o agentes [...]". 29 Entendemos que con este artículo se veta cualquier posibilidad de negociar colectivamente condiciones más favorables de desvinculación de la empresa. Otra arista de este problema está constituida por las razones que entran en juego en la elección de un Programa de retiro voluntario. Para autores como Salvia aquellas tienen relación con lo que llama una "acción económica

\footnotetext{
${ }^{28}$ Poder Ejecutivo Nacional: “Artículo 2”. En: Decreto 287. 7 de febrero de 1992.

${ }^{29}$ Poder Ejecutivo Nacional: “Artículo 6”. En: Decreto 287. 7 de febrero de 1992.
} 
estratégica", desplegada por los individuos "para optimizar sus condiciones personales y familiares de existencia" (SALVIA, 1995, p. 23).

El segundo proceso que mencionamos al inicio de este apartado es observable en las modificaciones introducidas en las Convenciones Colectivas de Trabajo que la Federación SUPE suscribe con Yacimientos Petrolíferos Fiscales. Es elocuente que, precisamente cuando el Ingeniero Estenssoro se hace cargo de la intervención de la petrolera estatal, se modifique la letra de los estatutos que regulan las relaciones laborales del sector petrolero, siendo que desde 1975 no se discutían.

En el período que nos ocupa, las modificaciones en el Convenio Colectivo de Trabajo tuvieron lugar en 1990, 1993 y 1997. Nos interesa revisar la letra de los acuerdos de esos años porque este procedimiento nos permitirá dar cuenta de la ofensiva contra el trabajo consolidada durante la administración Menem.

En diciembre de 1990 el Ministerio de Trabajo y Seguridad Social homologa la Convención Colectiva de Trabajo № 30/90 “E entre Federación SUPE e YPF. Ese nuevo convenio es producto de la necesidad del por entonces interventor J osé Estenssoro de flexibilizar las condiciones de trabajo en un sector poderosamente consolidado desde los primeros tiempos del peronismo. De este modo, una de las primeras reformas introducidas es la exclusión del Convenio de todo el personal que cumple funciones de mando o jefatura. Con lo cual se tiende a la desmonopolización de la representación del SUPE, cosa que efectivamente ocurre unos años después cuando se privatiza la empresa. A pesar de ello, en este convenio, el artículo 1 estipula que la Federación SUPE será el único órgano de representación de los trabajadores reconocido por el Ministerio de Trabajo y Seguridad Social y, como tal, deberá tener intervención en todo asunto vinculado al aseguramiento de los derechos y carrera de los trabajadores petroleros. La salvedad que establece este artículo es que "[...] la Entidad Gremial deberá tener intervención en todo lo que hace al aseguramiento de su carrera, compatible con la situación económica de la empresa". (ARGENTINA, 1990) Si nos detenemos un momento en esta precisión veremos que la estabilidad laboral de los trabajadores queda supeditada a la situación económica por la que atraviese la firma, así como también, unos incisos más adelante, se condicionan los beneficios sociales de los ypefianos a esa coyuntura, la cual en ese momento no es la más favorable para los trabajadores petroleros. ${ }^{30}$

$30 \mathrm{El}$ artículo 5 del Convenio Colectivo es más elocuente aún en este sentido: "Todo trabajador comprendido en este convenio que se encuentre vinculado a la Sociedad por un contrato individual por tiempo indeterminado, desde su ingreso tiene asegurada su evolución y progreso en tanto duren su contracción al trabajo y su buena conducta, con miras a alcanzar el desarrollo en el puesto o posición actual o futuras dentro de su campo ocupacional, respetando en todos los casos 
Así mismo, es visible en algunos artículos del convenio la incorporación de lo que determinados autores denominan mecanismos o formas de "flexibilización funcional". ${ }^{31}$ Con ello se refieren a la polivalencia, la ampliación de tareas y la formación de equipos de trabajo, esto es, "Los trabajadores deben ejecutar [...] distintas tareas, ya sea del mismo nivel de calificación o de niveles distintos. [Lo que] Implica romper con las características básicas de los antiguos Convenios Colectivos que establecían con claridad, calificaciones, categorías y tareas para cada puesto de trabajo". En todos los casos estaríamos en presencia, bien cabe recordar, de dispositivos tendientes a "[...] recuperar la tasa de ganancia y establecer una nueva relación entre Capital y Trabajo" (MARTÍNEZ, 1994, p. 19).

En el caso que nos ocupa estas formas de flexibilización cristalizan de la siguiente manera:

o Buscando la participación activa del trabajador en el proceso de trabajo. Se tiende a involucrar al obrero en la consecución de las metas empresarias, aunque utilizando ciertas formas de coacción, como veremos a continuación. El artículo 21 establece que para ascender de categoría, uno de los requisitos a evaluar es “[...] el comportamiento [del trabajador] como miembro de la comunidad del trabajo y su aptitud para participar activamente en la defensa y promoción de los intereses involucrados en la empresa". Si bien para el caso de YPF la identificación del los obreros con la firma es parte de un proceso más complejo y que tiene origen en la conformación de las villas obreras a partir de la radicación de la empresa en determinadas localidades, creemos que este artículo excede ese tipo de identificación para situarse en el plano de las transformaciones de la relación capital/trabajo que se producen en este momento histórico particular.

o Introduciendo en el convenio, muy sutilmente, la polivalencia funcional del trabajador, siendo que hasta entonces los puestos de trabajo se asignaban según niveles de calificación. Esto quedó establecido en el artículo 39 del Convenio que establecía que "La empresa podrá disponer el cambio de las funciones asignadas a los trabajadores [...]"; y en el artículo 28, donde se

el principio de igualdad de trato en identidad de situaciones y en el de conservar el empleo hasta alcanzar los límites de edad y tiempo de servicios necesarios para el goce de la jubilación ordinaria, siempre que no sean de incidencia económica tal que la empresa no pueda afrontarlos, o afecte sus intereses." [el resaltado es nuestro]. Ídem.

31 Castel se refiere de manera más genérica a la flexibilidad interna, es decir, a los cambios que las empresas introducen para que el personal se adapte a las transformaciones tecnológicas (CASTEL, 1998, p. 407). 
introduce la posibilidad de que la empresa determine traslados de personal “[...] por razones técnicas o económicas o de organización del trabajo, [y cuando] se opere la supresión del cargo, la desaparición de la función, la reorganización administrativa, el cambio tecnológico, el cese parcial o total de la actividad [...]”. Esto además es un resguardo por anticipado de la sociedad, que prevé los efectos que el Plan de Transformación Global tendrá sobre la fuerza de trabajo petrolera.

o Incorporando regímenes de capacitación para un mínimo del 10\% del personal por dependencia y por año (Art. 267). El capítulo X del Convenio Colectivo № 30/90 está dedicado íntegramente a este aspecto. En realidad, presumimos que el trasfondo de este apartado se vincula a la necesidad de generar mecanismos de reconversión laboral, previendo el inmenso número de despidos que se producirán a lo largo de estos años. Pese a nuestras presunciones, lo cierto es que en la letra del convenio se establece que las políticas de capacitaciones tenderán al mejoramiento de la eficacia y el nivel socio-tecnológico de la empresa y el trabajador. En ese sentido, uno de los artículos señala que tanto la Federación SUPE como la empresa:

\begin{abstract}
[...] coinciden en la necesidad de mejorar la productividad de la industria del petróleo, por medio de la modernización tecnológica, métodos de trabajos y optimización de las organizaciones, desarrollando una industria eficiente que se inserte en el mercado internacional, con rendimientos que alcancen una óptima competitividad, siendo la productividad un medio fundamental para la rentabilidad de las empresas y elevar la calidad de vida de los trabajadores. Las partes acordarán la introducción de modificaciones y/ o adelantos en las maquinarias y/o materias primas y/o métodos de trabajo, etc. que tiendan al mejor aprovechamiento de los recursos humanos y técnicos, y óptima utilización de los equipos productivos [...]. (ARGENTINA, 1990).
\end{abstract}

Si bien en esta primera modificación del convenio es visible la incorporación de formas de flexibilización laboral tanto en el ámbito del proceso productivo, como en el ámbito del mercado de trabajo, la tendencia se acentúa en los años posteriores. Así en la Convención Colectiva de Trabajo № 90/93 “E”, se reemplazan muchos artículos del anterior convenio, precarizando la situación de los agentes petroleros. Algunos de los recortes que pudimos observar al comparar ambos convenios fueron:

- La desaparición de licencias especiales con goce de haberes y de compensaciones especiales para aquellos trabajadores que presten servicios por sistema de turnos o turnos nocturnos y que "afecten la convivencia familiar normal”. Esto es interesante porque más allá de significar la incorporación de mecanismos de flexibilización salarial (MARTÍNEZ, 1994, 
p. 19) suponen transformaciones en los modos habituales en que los trabajadores petroleros vienen relacionándose con este tipo de empresa.

- Respecto a la protección de la salud son recortados innumerables beneficios, entre ellos: desaparecen los hospitales, policlínicos y unidades médicoasistenciales pertenecientes a la empresa; los desvinculados de la empresa no reciben más las prestaciones médicas 90 días después de ser apartados del cargo; los suspendidos dejan de tener derecho a la asistencia médica hasta que se resuelva su sumario administrativo. $\mathrm{Al}$ mismo tiempo desaparecen las consultas a domicilio, los tratamientos reeducativos, las franquicias para acompañantes, entre otras cosas.

- Quizás uno de los puntos más importantes y que marcan una inflexión en las relaciones capital/trabajo en este período es la incorporación de un "[...] sistema de pago por MAYOR EFICIENCIA, que reemplaza al de BONIFICACIÓN POR EFICIENCIA COLECTIVA”. En la Nota A. № 16 Nro. 20.012/92 del Convenio se justifica esta gratificación anual por mayor eficiencia, recurriendo a argumentos vinculados al involucramiento del trabajador con el proceso de reorganización de la firma. Esto no sólo se verá reflejado en los aumentos por productividad individual que se registren en el período, sino que también significa una fragmentación entre los obreros porque ahora ciertos mecanismos de acción y presión vinculados al control del proceso productivo por los trabajadores, son coartados por la competencia entre ellos.

La Federación S.U.P.E. vuelve a negociar el convenio en el año 1997. Para entonces continúa el recorte de beneficios sociales, especialmente en lo relativo a la salud. Comparando la letra de este convenio con la de 1993, podemos observar que se eliminaron íntegramente los artículos referidos al derecho de los agentes petroleros y sus familias de percibir prestaciones de orden médico-asistencial y económico-social. (Artículo 10 , inc. g” y “Capítulo IX ). Este aspecto que desaparece y que debe ser entendido como elemento constitutivo de una relación basada fundamentalmente en la forma injerencia de la empresa a nivel territorial y que excede lo meramente productivo, no sólo muestra la progresiva precarización de las condiciones materiales de existencia de los obreros, sino que también y - fundamentalmente - es un indicador 
de la desestructuración que se produce en estos enclaves tanto en el ámbito regional como en el ámbito de la reproducción de los trabajadores. ${ }^{32}$

Sumado a ello se incorpora explícitamente un artículo dedicado a la "polivalencia funcional", fundamentada en la necesidad de tender hacia una "óptima productividad”. Esto supone la eliminación de aquellos aspectos contractuales que protegen las categorías y la calificación de los trabajadores, permitiendo que el capital fuerce a un obrero calificado a realizar cualquier tarea no estipulada en el convenio.

En el nuevo convenio de relaciones, también se incorporan dispositivos de flexibilización salarial. Al respecto, se agrega un apartado que supone una mejora de sus ingresos - o su "ganancial retributivo"- en función a méritos y desempeño (Artículo 20). Ello se complementa con un acápite que establece la posibilidad de percibir remuneraciones adicionales en virtud a los objetivos alcanzados y/o la consecución del superávit de la empresa (Artículo 118). Todos estos aspectos contribuyen a fomentar la competencia entre trabajadores, y permiten al capital obtener mayores ganancias en base a un incremento de la productividad por obrero y en virtud al quiebre de la negociación salarial colectiva. Con ello queremos referirnos a que si bien el sindicato puede encarar una negociación salarial para todos los trabajadores por él representados, la incorporación de estas gratificaciones por mérito o desempeño desvirtúan esa negociación colectiva para dar lugar a esfuerzos individuales orientados a aumentar el nivel de ingreso personal y que, en definitiva, terminan beneficiando al capital, quien extrae mayor plusvalía en base al aumento de las horas/hombre trabajadas. Como contrapartida, se debilitan los mecanismos de presión con los que cuenta el trabajo y que permiten desarrollar mejores condiciones de negociación salarial. A todo este proceso hay que sumar el aumento del número de desocupados creados por la política de racionalización de personal llevada a cabo en el período y que constituirá un verdadero ejército industrial de reserva, que presionará hacia abajo los salarios.

32 Ejemplo de ello es también la supresión de un artículo en el cual se otorgan compensaciones a los trabajadores que deban desplazarse del lugar donde habitualmente prestan servicios o de domicilio y que supongan "la alteración de las condiciones individuales o familiares de vida [...]". Cfr. "Artículo 142". 


\section{Consideraciones Finales}

A lo largo de este trabajo intentamos observar las modificaciones que se ponen en marcha desde la implementación del Plan de Convertibilidad y la entrada al Plan Brady, especialmente en lo referido a las transformaciones en la relación salarial. La aplicación de los programas de ajuste estructural supuso no sólo la desregulación de los mercados sino también la incorporación de diferentes dispositivos de flexibilización laboral en la legislación vinculada al trabajo en Argentina.

La profundización de la precarización de los trabajadores a lo largo de la década del noventa nos habla de la emergencia de una "nueva cuestión social" que no sólo hace referencia al quiebre de la estabilidad que caracterizaba al trabajo asalariado, sino también a un proceso de desafiliación de los trabajadores, que remite a la pérdida de marcos de referencia derivadas de la creciente precariedad a la que son empujados.

Si bien no pudimos extendernos aquí en la descripción de todas las aristas que supone la "nueva cuestión social" en este caso particular, podemos señalar brevemente que las modificaciones que tienen lugar en YPF desde la sanción del Decreto 2778/91 inician un proceso de precarización no sólo de la situación de los trabajadores vinculados formalmente a la petrolera estatal, sino de las regiones estructuradas en torno a los yacimientos. Esto ocurre por la forma inserción territorial de la empresa estatal. YPF avanza no sólo en el ámbito de la producción sino también de la reproducción de los trabajadores, en la vida cotidiana, en las formas de organización de estos espacios. De ahí el profundo impacto que la desregulación y posterior privatización de la firma tuvieron no sólo en el ámbito del trabajo sino también a nivel de las economías regionales.

Situándonos específicamente en las Convenciones Colectivas de Trabajo, como expresión formal de la relación entre los trabajadores y el Estado, podemos señalar que algunos autores, como Dora Orlansky y Andrea Makón (2003, p. 10), consideran que la Federación SUPE negoció estas cláusulas a cambio del monopolio de la representación de los trabajadores del sector, la participación accionaria de los trabajadores a través del Programa de Propiedad Participada, subsidios para comprar parte de la empresa y contratos para dar trabajo a obreros despedidos y reorganizados en cooperativas y subsidios para la obra social.

En ese sentido, el SUPE responde a las reformas neoliberales de manera "conservadora adaptativa" (PALOMINO, 2005, p. 406), intentando preservar ciertos intereses corporativos a cambio de la aceptación de pautas flexibilizadoras que, como 
vimos, fueron incorporándose a lo largo de los noventa en los Convenios Colectivos de Trabajo que analizamos.

A nuestro modo de ver, estas estrategias sindicales del SUPE son parte de ese proceso más general atravesado por todo el movimiento obrero argentino y que tiene relación con las dificultades de los trabajadores organizados de superar el momento económico-corporativo. ${ }^{33}$

Esto no quiere decir que en los diferentes espacios regionales no se produjeran reacciones de las bases, sino que esas respuestas a la ofensiva del capital no lograron trascender de los espacios donde se gestaron y fueron perdiendo fuerza hasta que a fines de los '90, tuvieron lugar las puebladas en Salta y Neuquén. Pero éstas surgieron varios años después del proceso de racionalización de personal y se vinculan más bien a la precarización de las condiciones de existencia luego de que los montos percibidos por indemnizaciones desaparecieron $\mathrm{y}$ las posibilidades de reinvertirlos en emprendimientos productivos fracasaron.

\section{Referências}

ARGENTINA. Ministerio de Trabajo y Seguridad Social. Convención Colectiva de Trabajo, n. 30/90 “E”. Buenos Aires: Departamento de Publicaciones y Biblioteca, 1990.

BASUALDO, Eduardo; ASPIAZU, Daniel. Las privatizaciones en la Argentina. Génesis, desarrollo y los impactos estructurales. In: PETRAS, J ames; VELTMEYER, Henry (Comp.): Las privatizaciones y la desnacionalización de América Latina. Buenos Aires: Prometeo Libros, 2004.

BATTISTINI, Osvaldo. La democracia construida sobre la violencia. In: (Coord.). La atmósfera Incandescente: escritos políticos sobre la Argentina movilizada., Buenos Aires: Trabajo y Sociedad, 2002.

CASTEL, Robert. La metamorfosis de la cuestión social: una crónica del salariado. Buenos Aires: Paidós, 1998. Cap. 7-8.

33 Para comprender las razones por las cuales los trabajadores de YPF no lograron consolidar una ofensiva coordinada contra la política "desreguladora" pensamos que nos puede ser útil la categorización gramsciana de momento político en la medida en que nos clarifica o nos permite definir la relación de fuerzas que prevalece en este período. Para Gramsci, analizar el momento político de una determinada formación histórica permite la “[...] valoración del grado de homogeneidad, autoconciencia y organización alcanzado por los diferentes grupos sociales" (GRAMSCI, 1995, p. 57). Pueden ser tres los grados en que se halla la conciencia colectiva de ese momento político, a saber: a) Económico-corporativo: se siente la unidad de un grupo profesional y el deber de organizar a ese grupo, pero no se siente aún la necesidad de organizar al grupo más vasto; b) Económico: Se logra una conciencia de solidaridad entre todos los miembros pero únicamente en lo económico; y c) Político: Se logra conciencia de los propios intereses corporativos, superando el límite económico del momento anterio. 
CENTRAL DE LOS TRABAJADORES ARGENTINOS. Disponivel em: <http:// www.cta.org.ar/ ?lang=es>. Acesso em: 10 ago. 2011.

DE DICCO, Ricardo Andrés. ¿Crisis energética en Argentina? Diagnóstico para comprender qué hay detrás de la "crisis". El Salvador: Instituto de Investigación en Ciencias Sociales. Facultad de Ciencias Sociales. Universidad de El Salvador, 2004. (Documento de Trabajo, no 22).

\section{FEDERACIÓN DE LOS TRABAJ ADORES DE LA ENERGÍA DE LA REPÚBLICA} ARGENTINA. Origen y desarrollo de la industria del petróleo en Argentina y Latinoamérica. Disponible en:<http:// www.sindluzyfuerzamdp.org.ar/ FeTERA/index>. Aceso en: jun. 2011.

GODIO, J ulio. Historia del Movimiento Obrero Argentino 1870-2000. Buenos Aires: Corregidor, 2000. $2 \mathrm{t}$.

GRAMSCI, Antonio. Notas sobre Maquiavelo, sobre la política y sobre el Estado Moderno. Buenos Aires: Nueva Visión, 1995.

HERRERA, César V.; GARCÍA, Marcelo. A diez años de la privatización de YPF. Análisis y consecuencias en la Argentina y en la Cuenca del Golfo San J orge. Centro Regional de Estudios Económicos de la Patagonia Central, 2003.

KLACHKO, Paula. Las consecuencias políticas y sociales de la privatización de YPF. El impacto en las localidades de Cutral Có y Plaza Huincul. Realidad Económica, n. 209, 1 ene. a 15 feb., 2005.

MARTÍNEZ, Oscar A. (Comp.). Pensando la Reconversión. una visión crítica de la flexibilidad y la calidad total. Buenos Aires: CIPES, 1994.

MARX, Karl. El Capital. Crítica de la Economía Política. México: Fondo de Cultura Económica, 1999. t. 1-3.

MUÑOZ, Irene; CAMPIONE, Daniel. Estado y Sociedad. De Alfonsín a Menem. Buenos Aires: Letra Bue-na, 1994.

MUSACCHIO, Andrés. La estrategia exportadora en la Argentina: ¿necesidad, objetivo o utopía?. In: CLACSO. La Globalización Económico Financiera. Su impacto en América Latina. J ulio Gambina, 2002

NEFFA, J ulio César. Modos de regulación, regímenes de acumulación y sus crisis en Argentina (1880-1996): una contribución a su estudio desde la teoría de la regulación. Buenos Aires: Eudeba, 1998.

Marta Novick; Maria A. Gallart. (Org.). Competitividad, redes productivas y competencias laborales. Buenos Aires: Cinterfor, 1997.

ORLANSKY, Dora; MAKON, Andrea. De la sindicalización a la informalidad. El caso de Repsol-YPF. Revista Argentina de Sociología, Buenos Aires, Año 1, n. 1, Nov.-Dic., 2003. 
PALOMINO, Héctor. Los cambios en el mundo del trabajo y los dilemas sindicales. In: SURIANO, J uan (Comp.): Nueva Historia Argentina: dictadura y democracia (19762001). Buenos Aires: Sudamericana, 2005. t. 10.

REDONDO, Nélida (Coord.). La reinserción laboral de los empleados desplazados del Estado: El caso dela Destilería La Plata de YPF. Buenos Aires: Dirección Nacional de Estudios y Documentación. Instituto Nacional de la Administración Pública, 1997. (Serie II. Estado y sociedad. Documento, n. 38).

ROFMAN, Alejandro. Las economías regionales a fines del siglo XX. Los circuitos del petróleo, del carbón y del azúcar. Buenos Aires: Ed. Ariel, 1999.

ROITTER, Daniel. La privatización de YPF: transformación en la empresa, la estrategia de venta en la oferta pública, acceso de la Argentina a los mercados internacionales de capitales. Boletín Informativo Techint, n. 277, Ene.-mar., 1994.

SALVIA, Agustín; MUÑOZ, Cristian; FEDERICO, Andrea. La adopción del retiro voluntario por trabajadores de una empresa minera. Una decisión ajustada a condiciones sociales de existencia. Revista Waxen, Patagonia Austral, n. 6, 1995.

TRINCHERO, Héctor Hugo; LEGUIZAMÓN, J uan Martín. Hidrocarburos, dinámica del capital y cuestión social en el Norte Argentino. In: BELLI, Elena, SLAVUTSKY, Ricardo; TRINCHERO, Héctor Hugo (Comp.). La cuenca del Río Bermejo: una formación social de frontera. Buenos Aires: Ed. Reunir, 2004. 


\section{Fuentes}

Boletín Oficial. Decreto 2074. 5 de octubre de 1990.

Congreso de la Nación Argentina. Ley 23.928. 28 de marzo de 1991.

Congreso de la Nación Argentina. Ley 24.465. 23 de marzo de 1995.

Digesto A.z , n. 106, 1997.

INDEC. Encuesta Permanente de Hogares. Años 1974-2003

Microsemanario, años 1990-1992

Poder Ejecutivo Nacional. Decreto 2778. 31 de diciembre de 1990.

Poder Ejecutivo Nacional: Ley Nacional de Empleo № 24.013, noviembre de 1991

Poder Ejecutivo Nacional: Decreto 2284. 30 de octubre de 1991.

Poder Ejecutivo Nacional: Decreto 287. 7 de febrero de 1992.

Colaboración recibida en 04/ 07/ 2010 y aprobada en 12/ 03/ 2011. 